\title{
Gallstone disease in Peruvian coastal natives and highland migrants
}

\author{
P L Moro, W Checkley, R H Gilman, L Cabrera, A G Lescano, J J Bonilla, B Silva
}

Research Department, Proyectos de Informatica, Salud, Medicina, y Agricultura (A B PRISMA), Lima, Peru P L Moro W Checkley L Cabrera

A G Lescano

Department of International Health, Johns Hopkins School of Hygiene and Public Health, Baltimore, Maryland, USA

W Checkley

R H Gilman

A G Lescano

Department of Pathology, Universidad Peruana Cayetano Heredia, Lima, Peru R H Gilman

Department of Gastroenterology, Policlinico Peruano-Japones, Lima, Peru J J Bonilla

Department of Radiology, Hospital Nacional Arzobispo Loayza, Lima, Peru B Silva

Correspondence to: Professor R H Gilman, Johns Hopkins University School of Hygiene and Public Health,

Department of International Health, 615 North Wolfe Street, Room W3503, Baltimore, MD 21205, USA

Accepted for publication 22 September 1999

\begin{abstract}
Background-In a previous study, we found that gallstones were a common occurrence in the high altitude villages of the Peruvian Andes.

Aims-To determine if high altitude $(\geqslant 1500 \mathrm{~m}$ ) is a contributing risk factor for gallstone disease.

Methods-We conducted a cross sectional study in a periurban community in Lima, Peru, and compared the prevalence of gallstone disease between coastal natives, highland (Sierra) natives and Sierra natives who had migrated to the coast. We also compared the prevalence rates from this study with those from a previous study conducted at high altitude. We examined 1534 subjects $>15$ years of age for gallstone disease. Subjects were interviewed for the presence or absence of risk factors.
\end{abstract}

Results-Gallstone disease was more common in females (16.1 cases per 100, 95\% CI 13.8-18.2) than in males (10.7 per 100, 95\% CI 8.0-13.4). Females had a greater risk of gallstone disease, especially if they had used oral contraception and/or had four or more children. The age adjusted prevalence was not significantly different between coastal natives, Sierra migrants, and Andean villagers. The prevalence of gallstone disease was not associated with time since migration or with having native Sierra parents. After adjusting for other risk factors, Sierra natives who migrated to the coast had a lower prevalence of gallstone disease than coastal natives (odds ratio $0.74,95 \%$ CI 0.58-0.94).

Conclusions-This study indicates that high altitude is not a positive risk factor for gallstone disease and confirms that this disease is common in Peruvians, which may be attributable to PeruvianIndian ethnicity.

(Gut 2000;46:569-573)

Keywords: gallstone disease; cholelithiasis; high altitude; risk factors; epidemiology; Peru

Gallstone disease is generally considered less of a health problem in developing than in developed countries. In the past decade, however, there has been an increasing number of reports indicating that gallstones are a common cause of hospitalisation in developing countries. ${ }^{1-3}$ Further evidence of its ubiquitous nature in developing countries has come from a recent population based study in Peru which found a high rate of asymptomatic gallstones. ${ }^{4}$

The advent of ultrasound and greater access to health care in remote areas of developing countries have improved the detection of gallstone disease in these regions. In spite of recent improvements in diagnostic methods and increased awareness of the disease, data on the epidemiology of gallstones in South America are still lacking. To improve our understanding of the disease in Peru, we conducted a prevalence study using a portable ultrasound in three villages of the Peruvian Andes ( $>3000 \mathrm{~m}$ above sea level) and found gallstone disease rates similar to those of Mexican-Americans from the $\mathrm{USA}^{45}$ but greater than those reported in most European or Asian countries. ${ }^{4-9}$

High rates of gallstone disease were reported in the high altitude villagers of Ladakh, India ${ }^{10}$ who, because of slow intestine transit time, have high rates of constipation, a risk factor for gallstone disease. ${ }^{11}$ Gallstone formation may be increased at high altitude because slow intestinal transit can lead to increased bilirubin absorption and higher bile concentrations in the gall bladder. ${ }^{12} 13$ In addition, increased blood cell formation and hence increased haemolysis may increase levels of bilirubin pigments with an increased risk of pigment gallstones. ${ }^{14}$

If high altitude is an important risk factor for gallstone disease, we would expect a higher risk of the disease in individuals living in high altitude villages compared with those living at low altitude. In our previous study we could not explore the effect of altitude on gallstone formation because of the lack of comparative community based baseline data for lower altitude villages. In this investigation, we studied the association between altitude and gallstone disease using cross sectional data from a Peruvian shanty town (pueblo joven) in the capital city of Lima, located at sea level. A pueblo joven provides an appropriate setting to study the association between altitude and gallstone disease because of the considerable migration that occurs from the Andes and from other regions of Peru to Lima. In this study, we compared the rates of gallstone disease between coastal natives and highland (Sierra) natives who migrated to the coast. Data from both of these groups were compared with prevalence rates from highland Andean villagers determined in a previous study.

Abbreviations used in this paper: $\mathrm{BMI}$, body mass index. 
Materials and methods

STUDY SITE

The study was conducted between January 1997 and August 1997 in Pampas de San Juan, a pueblo joven on the outskirts of Lima, Peru, with approximately 40425 inhabitants. A large proportion of adults from this community have migrated from rural areas in the Peruvian Andes to Lima and are casual workers (day labourers or street vendors). Most households have access to electricity but lack running water or sewage. The early settlers live closer downhill in the more established households which are made of brick and have better access to paved roads while the more recent settlers live uphill in houses constructed of wooden poles, bamboo shoots, and tin roofs. A census was carried out in the community within the past year by A B PRISMA, a local nongovernmental organisation.

All subjects were asked to sign a written consent form before participation in the study. The study was approved by the internal review board of A B PRISMA and the Committee on Human Research of Johns Hopkins School of Hygiene and Public Health.

DATA COLLECTION

A total of 1000 households $(2.8 \%$ of the total households in the community) were initially selected at random from the census and all individuals $>15$ years of age from each household were invited to participate in the study. The proportion of older subjects (i.e. $>50$ years of age), which comprise less than $6 \%$ of the total population, was increased by inviting all individuals from the community who were $>50$ years of age to participate in the study. We asked participants to attend the local health post after an overnight fast. We examined subjects for gallstones using an Aloka SSD-260 portable ultrasonograph $(3.5 \mathrm{MHz})$. Subjects were classified as having gallstone disease if they met the following criteria: (1) visible gall bladder lumen presenting echoes with an acoustic shadow (the echoes were required to be movable except when impeded by size); (2) those having an echo with acoustic shadows and no gall bladder lumen presenting a gall bladder filled with stones, and (3) no gall bladder lumen in subjects with a history of cholecystectomy and an appropriate scar. ${ }^{15}$ All subjects were asked for specific symptoms associated with gallstone disease. Biliary pain caused by gallstones was defined as one or more distinct bouts of upper abdominal pain (above the umbilicus) during the past year lasting for at least 30 minutes.

To identify risk factors for the disease, we used a questionnaire and interviewed subjects at the time of their visit to the health post. To reduce bias, we conducted the interview before the ultrasound examination. Ultrasonographers did not participate as interviewers. All individuals were asked about their and their parent's place of birth, educational level, level of alcohol consumption, and whether or not they suffered from constipation (defined as no defecation for $>1$ day, hard consistency of stools and straining at defecation). Females were asked about the number of children they had and whether they had ever used oral contraception. Subjects who were not from the coastal regions were asked how long it was since they migrated to Lima. We also measured each individual's weight and height at the time of the visit. Body mass index (BMI) was calculated for each individual $\left(\mathrm{kg} / \mathrm{m}^{2}\right)$.

We classified alcohol consumption as none, at least once a year, or at least once a month (drinking patterns in these areas are usually weekend or festival binges). Educational level was classified as up to high school or completed high school and beyond, and multiparity was defined as four or more children. We stratified BMI into three groups. If an individual was born in a region $<1500 \mathrm{~m}$ above sea level, he was considered a coastal native; if an individual was born in a region of the Peruvian Andes $\geqslant 1500 \mathrm{~m}$ above sea level he was considered a Sierra native migrant (a highland native who had migrated to the coast). We classified time since migration to Lima as $<10$ or $>10$ years. Individuals born in the tropical rainforest regions in Peru were not included.

STUDY SAMPLE

Thirty seven percent $(1042 / 2840)$ of subjects $>15$ years of age selected from households and $20 \%(492 / 2409)$ aged $>50$ years of age agreed to participate in the study. Of the subjects $>15$ years of age selected from households, mean age of the participants was 29.3 years and of the nonparticipants, 34.8 years $(\mathrm{p}<0.001$, $\mathrm{t}$ test). Females $(749 / 1471 ; 51 \%)$ were more likely to participate than males (293/1076; $27 \%)(p<0.001$, Fisher's exact test). Of the subjects $>50$ years of age that agreed to participate in the study, mean age of the participants was 59.9 years and that of the nonparticipants, 62.40 years $(\mathrm{p}<0.001$, $\mathrm{t}$ test $)$. Females $(288 / 1176 ; 24 \%)$ were more likely to participate than males $(204 / 1233 ; 17 \%)$ ( $p<0.001$, Fisher's exact test).

A total of 1534 individuals consented to participate in the study, were examined for gallstone disease, and were interviewed for risk factors. A multivariate analysis of risk factors for gallstone disease was performed using 1513 individuals with no missing data (i.e. less than $2 \%$ of individuals did not answer at least one of the questions in the interview or did not have their answer noted by the interviewer).

\section{BIOSTATISTICAL METHODS}

To compare the prevalence rates of gallstone disease between the different groups, we adjusted the rates for age using the direct method of standardisation, as previously described. ${ }^{16}$ We used the Pampas de San Juan de Miraflores sample as the standard population for calculation of age adjusted rates. We calculated the $95 \%$ CI for age adjusted rates, as previously described. ${ }^{16}$ Standardisation allowed us to make comparisons in prevalence rates between males and females and between coastal natives and Sierra native migrants. We also examined whether time since migration or parent's place of birth was associated with gallstone disease. Age standardised prevalence 
Table 1 Age stratified prevalence of gallstone disease in males. Rates were also stratified by geographical region: coastal natives, Sierra migrants stratified by time since migration, and Andean villages. Rate equals gallstone disease cases per 100 persons ( $n=$ number of people examined for gallstone disease)

\begin{tabular}{|c|c|c|c|c|c|c|c|c|}
\hline \multirow[b]{3}{*}{ Age (years) } & \multicolumn{8}{|c|}{ Males } \\
\hline & \multicolumn{2}{|c|}{ Coastal natives } & \multicolumn{2}{|c|}{$\begin{array}{l}\text { Sierra natives } \\
<10 \text { y migration }\end{array}$} & \multicolumn{2}{|c|}{$\begin{array}{l}\text { Sierra natives } \\
\geqslant 10 \text { y migration }\end{array}$} & \multicolumn{2}{|c|}{ Andean villages } \\
\hline & $n$ & $\%$ Disease & $n$ & $\%$ Disease & $n$ & $\%$ Disease & $n$ & $\%$ Disease \\
\hline $15-24$ & 46 & 0.0 & 7 & 0.0 & 17 & 0.0 & 57 & 0.0 \\
\hline $25-34$ & 25 & 3.8 & 11 & 18.2 & 36 & 2.8 & 69 & 1.5 \\
\hline $34-44$ & 26 & 10.3 & 5 & 0.0 & 53 & 5.7 & 61 & 4.9 \\
\hline $45-54$ & 21 & 19.2 & 2 & 0.0 & 63 & 7.9 & 65 & 9.2 \\
\hline $55-64$ & 21 & 22.2 & 4 & 0.0 & 57 & 10.5 & 40 & 20.0 \\
\hline $65+$ & 9 & 30.8 & 7 & 42.9 & 66 & 21.2 & 36 & 38.9 \\
\hline Total & 167 & 11.4 & 36 & 13.9 & 292 & 9.9 & 328 & 9.8 \\
\hline Age adjusted rates $(95 \% \mathrm{CI})$ & \multicolumn{2}{|c|}{$7.0(3.1-10.9)$} & \multicolumn{2}{|c|}{$4.8(0.0-9.9)$} & \multicolumn{2}{|c|}{$3.7(1.5-5.9)$} & \multicolumn{2}{|c|}{$4.0(2.2-5.9)$} \\
\hline
\end{tabular}

rates from this study were also compared with those from our previous study conducted in the Peruvian Andes (at $>3000 \mathrm{~m}$ above sea level).

To determine the risk factors associated with gallstone disease, we used multiple logistic regression. The dependent variable was the presence or absence of gallstone disease. Independent variables were age, sex, alcohol consumption, BMI, educational level, constipation, place of birth (i.e. coast or highlands), and interaction terms for female sex and multiparity, in addition to female sex and oral contraception. The odds ratio for each independent variable estimates the effect of that variable on gallstone disease after controlling for confounding of other variables in the model. From the regression model, we calculated pertinent odds ratios and $95 \%$ CI. ${ }^{16}$

More than $60 \%(914 / 1513)$ of participants included in the regression analysis shared the same household with at least one other individual in the sample. The household cluster size of the sample varied from one to nine individuals per household. It is possible that part of the variability in the data may be explained by a household effect. We found it necessary, therefore, to account for the serial dependence among individuals of the same household in our regression analysis. To do so, we used alternating logistic regression analysis. ${ }^{17}$ This method allowed us to simultaneously fit odds ratios for each risk factor and an odds ratio to measure the association among individuals from the same household. The latter odds ratio, known as the paired odds ratio, measures the odds of gallstone disease for all individuals based on the disease status of other individuals in the same household. A paired odds ratio different from 1 (the null hypothesis) indicates the existence of a household effect (e.g. an odds ratio $>1$ suggests that individuals from the same household share a common trait that makes them more susceptible to the disease). The alternating logistic regressions model was fitted using the OSWALD algorithm developed for the S-Plus statistical software (MathSoft, Seattle, Washington, USA). Simple $2 \times 2$ table comparisons were performed using Fisher's exact test.

\section{Results}

The crude prevalence rate of gallstone disease was $14.3 \%(219 / 1534)$. When stratified by sex, females had a significantly greater rate of gallstone disease than males $(16.0 \%$ v $10.7 \%$; $\mathrm{p}<0.01$, Fisher's exact test) and cholecystectomy $(3.4 \% v 1.0 \% ; \mathrm{p}<0.01$, Fisher's exact test). Abdominal pain, however, was a poor indicator of symptomatic gallstones. Symptoms were as common in subjects with gallstone disease $(29 / 219 ; 13.2 \%)$ as in those without gallstone disease $(203 / 1315 ; 15.4 \%)$ $(\mathrm{p}=0.48$, Fisher's exact test $)$.

Table 1 compares the age stratified prevalence rates of gallstone disease in males among coastal natives, Sierra native migrants stratified by time since migration, and Andean (Sierra) villagers. Table 2 shows the same age stratified rates as Table 1 for females. Females had a significantly higher age adjusted prevalence rate of gallstone disease than males, independent of their place of birth. Time since migration to the coast was not significantly associated with gallstone disease. There were no significant differences in the age adjusted rates of disease between coastal natives, Sierra migrants, and

Table 2 Age stratified prevalence of gallstone disease in females. Rates were also stratified by geographical region: coastal natives, Sierra migrants stratified by time since migration, and Andean villages. Rate equals gallstone disease cases per 100 persons ( $n=$ number of people examined for gallstone disease)

\begin{tabular}{|c|c|c|c|c|c|c|c|c|}
\hline \multirow[b]{3}{*}{ Age (years) } & \multicolumn{8}{|c|}{ Females } \\
\hline & \multicolumn{2}{|c|}{ Coastal natives } & \multicolumn{2}{|c|}{$\begin{array}{l}\text { Sierra natives } \\
<10 \text { y migration }\end{array}$} & \multicolumn{2}{|c|}{$\begin{array}{l}\text { Sierra natives } \\
\geqslant 10 \text { y migration }\end{array}$} & \multicolumn{2}{|c|}{ Andean villages } \\
\hline & $n$ & $\%$ Disease & $n$ & $\%$ Disease & $n$ & $\%$ Disease & $n$ & $\%$ Disease \\
\hline $15-24$ & 132 & 0.0 & 21 & 4.8 & 41 & 4.9 & 120 & 5.8 \\
\hline $25-34$ & 72 & 9.7 & 21 & 14.3 & 88 & 11.4 & 157 & 15.9 \\
\hline $34-44$ & 81 & 17.3 & 16 & 6.3 & 134 & 6.7 & 139 & 21.6 \\
\hline $45-54$ & 49 & 26.5 & 8 & 37.5 & 95 & 17.9 & 67 & 29.9 \\
\hline $55-64$ & 38 & 36.8 & 4 & 50.0 & 92 & 27.2 & 48 & 35.4 \\
\hline $65+$ & 27 & 37.0 & 14 & 7.1 & 90 & 33.3 & 50 & 40.0 \\
\hline Total & 399 & 14.5 & & 13.1 & 540 & 17.2 & 581 & 20.5 \\
\hline Age adjusted rates $(95 \% \mathrm{CI})$ & \multicolumn{2}{|c|}{$11.6(8.5-14.7)$} & \multicolumn{2}{|c|}{$12.2(5.4-19.1)$} & \multicolumn{2}{|c|}{$9.4(6.4-12.5)$} & \multicolumn{2}{|c|}{$16.5(13.6-19.5$} \\
\hline
\end{tabular}


Table 3 Risk factor analysis for gallstone disease among individuals from Las Pampas de San fuan de Miraflores, Lima, Peru, 1997. The odds ratio (OR) of each risk factor was obtained from a multivariate regression model that contains all the risk factors listed in this table

\begin{tabular}{|c|c|c|c|c|}
\hline \multirow[b]{2}{*}{ Risk factor } & \multirow[b]{2}{*}{$n$} & \multirow{2}{*}{$\begin{array}{l}\text { Gallstone } \\
\text { disease (\%) }\end{array}$} & \multicolumn{2}{|c|}{ Regression analysis } \\
\hline & & & $O R$ & $(95 \% C I)$ \\
\hline \multicolumn{5}{|l|}{ Age (years) } \\
\hline $15-34$ & 504 & 5.56 & 1.00 & \\
\hline $35-54$ & 566 & 12.90 & 1.97 & $(1.35-2.86)$ \\
\hline $55+$ & 443 & 26.64 & 5.25 & $(3.59-7.68)$ \\
\hline \multicolumn{5}{|l|}{ Sex, contraceptive use, parity } \\
\hline Male & 497 & 10.66 & 1.00 & \\
\hline Female, never used, $<4$ & 469 & 8.32 & 1.24 & $(0.86-1.78)$ \\
\hline Female, never used, $\geqslant 4$ & 505 & 23.76 & 2.04 & $(1.54-2.69)$ \\
\hline Female, ever used, $<4$ & 28 & 14.29 & 2.98 & $(1.07-8.32)$ \\
\hline Female, ever used, $\geqslant 4$ & 14 & 21.43 & 3.77 & $(1.10-12.83)$ \\
\hline \multicolumn{5}{|l|}{ Body mass index $\left(\mathrm{kg} / \mathrm{m}^{2}\right)$} \\
\hline $16.48-24.11$ & 504 & 9.52 & 1.00 & \\
\hline $24.12-27.56$ & 533 & 13.13 & 1.28 & $(0.96-1.70)$ \\
\hline $27.57-43.74$ & 476 & 21.22 & 1.97 & $(1.47-2.63)$ \\
\hline \multicolumn{5}{|l|}{ Alcohol consumption } \\
\hline None & 958 & 15.87 & 1.00 & \\
\hline At least once a year & 263 & 12.55 & 0.89 & $(0.66-1.21)$ \\
\hline At least once a month & 292 & 11.64 & 1.04 & $(0.80-1.33)$ \\
\hline \multicolumn{5}{|l|}{ Educational level } \\
\hline Up to high school & 196 & 27.04 & 1.00 & \\
\hline High school or beyond & 1317 & 12.60 & 0.94 & $(0.70-1.27)$ \\
\hline \multicolumn{5}{|l|}{ Constipation } \\
\hline Not constipated & 1188 & 13.80 & 1.00 & \\
\hline Constipated & 325 & 16.92 & 1.24 & $(0.95-1.62)$ \\
\hline \multicolumn{5}{|l|}{ Place of birth } \\
\hline Costa & 551 & 13.97 & 1.00 & \\
\hline Sierra migrants & 962 & 14.76 & 0.74 & $(0.58-0.94)$ \\
\hline
\end{tabular}

Andean villages in both males and females, except for one particular subgroup (females in the Sierra native migrant category had a significantly lower prevalence than Andean females at the 0.05 level).

There were no significant differences in the age adjusted rates of gallstone disease, independent of parent's place of birth. Risk factor analysis is presented in table 3 . The odds of gallstone disease increased significantly with age and BMI. After adjusting for all other risk factors, Sierra natives migrating to the coast had a significantly lower prevalence of gallstone disease than coastal natives (odds ratio 0.74, 95\% CI 0.58-0.94). Females were at greater risk of having gallstone disease, especially if they had ever used oral contraception and/or were multiparous.

Our analysis revealed a marginally significant household effect (paired odds ratio 1.82, 95\% CI 0.99-3.32) not explained by the risk factors we included in the questionnaire. This paired odds ratio suggests that individuals from a household where there is another individual with gallstone disease have about twice the odds of having the disease relative to those from a household where no other cases are present.

\section{Discussion}

Our investigation provides further support for the hypothesis that gallstone disease is common in Peru. High altitude, however, does not appear to be a positive risk factor for gallstone disease, as originally hypothesised. Contrary to our expectations, coastal natives presented a greater rate of gallstone disease than Sierra migrants. These results, however, were not consistent, as noted by the fact that Sierra native females who had migrated $<10$ years ago had higher rates of gallstone disease than coastal females, and Sierra native males who had migrated $<10$ years ago had lower rates of gallstone disease than coastal males. Furthermore, Andean villagers did not have a significantly greater risk of gallstone disease than coastal natives for both males and females.

If high altitude were a positive risk factor for gallstone disease, we would have expected to find the highest prevalence of gallstone disease among Andean villagers followed by Sierra native migrants. Coastal natives would have had the lowest prevalence. Furthermore, if high altitude Peruvian villagers had a genetic component that increased their risk of gallstone disease, we would expect subjects with Sierra native parents to have a higher prevalence than subjects with native coastal parents. In this investigation, however, we were unable to confirm any of these hypotheses. Coastal natives even tended to have a higher prevalence of gallstone disease than Sierra native migrants. Our results indicate that high altitude itself is not a risk factor for gallstone disease. Instead, we found a marginally significant household effect that was not explained by any of the risk factors included in our analysis. This finding suggests that some shared trait among individuals of the same household, such as genetic make up, environment or diet, may explain part of the prevalence of gallstone disease observed in Pampas de San Juan de Miraflores. Our finding that Peruvians and MexicanAmericans have similar rates of gallstone disease $^{4}$ suggests that these ethnic groups share a genetic trait that makes them more susceptible to gallstone formation. It is possible that this genetic trait is also shared with related ethnic groups, such as the Pima Indians and other South American Indian groups.

The estimated prevalence rate of cholecystectomy in subjects with gallstone disease from Pampas (9\% in males and $21 \%$ in females) is similar to the rate in Andean villagers but lower than rates reported for Mexican-Americans ${ }^{5}$ and Europeans. ${ }^{6}$ The lower prevalence of cholecystectomy in our population may be explained by the low prevalence of symptomatic gallstones $(2.2 \%$ for males and $0.6 \%$ for males) or by the limited access to health care services in these regions. Other studies have shown similar rates of symptomatic gallstones. Our study, however, unlike others, was not biased by high rates of cholecystectomy.

In our study, females had a significantly greater prevalence of cholecystectomy than males but not a greater prevalence of symptomatic gallstones. Females also appeared to develop gallstones at a younger age. This higher prevalence may be a consequence of earlier presentation of gallstone disease and thus a longer duration of disease exposure in females. It is possible that the duration of disease exposure results in an increased risk of cholecystectomy. Therefore, the higher rates of cholecystectomy observed in females relative to males may be explained in part by their increased exposure time to gallstones rather than sex alone. This concept of exposure years is akin to that discussed in environmental and 
smoking studies which find that longer duration of exposure is associated with increased morbidity and mortality.

Females may be at increased risk of developing gallstone disease earlier in life than males as a result of risk factors such as increased parity and oral contraception. Our risk factor analysis revealed that the odds of gallstone disease in females who were multiparous and/or had ever used oral contraceptives was 204-377\% greater than that of males of similar age. In contrast, in females with no extraneous risk factors the odds were $24 \%$, not significantly different from males of a similar age. These results suggest that the commonly perceived notion that females have a greater risk of developing gallstone disease than males may be largely attributed to the presence of extraneous risk factors, such as increased parity and oral contraception rather than sex alone. A similar positive association between increased parity and gallstone disease was noted among European populations, including Danish ${ }^{15}$ and Italian women, ${ }^{11} 18$ and among women from Kashmir, India. ${ }^{3}$ Similarly, oral contraceptive use has been associated with an increased risk of gallstone disease in Hispanic ${ }^{19}$ and Danish women. ${ }^{15}$ However, some studies have not found a positive association. ${ }^{11} 18$

An important limitation of our study was the low rate of participation among study subjects, especially males. Most nonparticipants were working when examinations were performed and could not be reached. Females were more likely to participate than males. This bias may contribute to an increase in the crude prevalence of gallstone disease in the total population. However, we minimised this bias by stratifying our data by sex. The effect of selection bias in this study was to increase the prevalence because of the over representation of females but to decrease the prevalence because of the over representation of younger age groups. Although both operators were highly experienced (BS and JB), reader variability may also lead to errors in measurement.

In our investigation, body composition was an important risk factor for gallstone disease. The Peruvian population is generally not obese: less than $16 \%(247 / 1534)$ of individuals had a BMI $\geqslant 30 \mathrm{~kg} / \mathrm{m}^{2}$. Fat consumption in Pampas de San Juan de Miraflores is low. A recent report found that, on average, individuals from Pampas consume 50\% less fat than the minimum recommendation of the FDA. ${ }^{17} \mathrm{Leg}-$ ume intake, also hypothesised to be a risk fac- tor for gallstone disease, ${ }^{18}$ is not a staple food of the Peruvian diet. ${ }^{19}$ Therefore, genetic make up may explain a larger proportion of the case of gallstone disease in Peru than diet or anthropometric status. Our results lend further support to the hypothesis that Peruvian-Indian populations have an inherited predisposition to stone formation.

The study was funded in part by an NIH grant U01-A135894 awarded to the Johns Hopkins University, a Fundación Instituto Hipólito Unanue grant awarded to A B PRISMA, and by the charitable RG-ER fund for the advancement of Andean research. We thank Drs S Gange, M D Chestnut, and C M Fillmore for helpful comments, Ms J Moro for technical assistanillmore for helpful comments, Ms J Moro for technical assistance, and Ms J B Phu and Ms D Sara for editorial assistance. The OSWALD algorithm for the $S$ Plus statistical software, developed by Drs D Smith, B Robertson, and P Diggle, was
obtained from STATLIB.

1 Covarrubias C, Valdivieso V, Nervi F. Epidemiology of gallCovarrubias C, Valdivieso V, Nervi F. Epidemiology of gall-
stones in Chile. In: Capocaccia L, ed. Epidemiology and prestones in Chile. In: Capocaccia L, ed. Epidemiology and pre-
vention of gallstone disease. Lancaster: MTP Press, 1984:26vent 30 .

2 Sanchez NM, Jessurun J, Ponciano-Rodriguez G, et al. Prevalence of gallstone disease in Mexico: A necropsy study. Dig Dis Sci 1993;38:680-3.

3 Khuroo MS, Mahajan R, Zargar SA, et al. Prevalence of biliary tract disease in India: A sonographic study in adult population in Kashmir. Gut 1989;30:201-5.

4 Moro PL, Checkley W, Gilman RH, et al. Gallstone disease in high-altitude Peruvian rural populations. Am $\mathcal{F}$ Gastroenterol 1999;94:153-8.

5 Maurer KR, Everhart JE, Ezzati TM, et al. Prevalence of gallstone disease in Hispanic populations in the United States. Gastroenterology 1989;96:487-92.

6 Heaton KW, Braddon FEM, Mountford RA, et al. Symptomatic and silent gallstones in the community. Gut 1991;32: 316-20.

7 Attili AF, Carulli N, Roda E, et al. Epidemiology of gallstone disease in Italy: Prevalence data of the multicenter Italian study on cholelithiasis (MICOL). Am F Epidemiol 1995; 141:158-65.

141:158-65.
8 Jorgensen T. Prevalence of gallstones in a Danish population. Am f Epidemiol 1987;126:912-21.

9 Nomura H, Kashiwagi S, Hayashi J, et al. Prevalence of gallstone disease in a general population of Okinawa, Japan. Am F Epidemiol 1988;128:598-605.

10 Spathis A, Heaton KW, Emmett PM, et al. Gallstones in a community free of obesity but prone to slow intestinal ransit. Eur f Gastroenterol Hepatol 1997;9:201-6.

11 Misciagna G, Leoci C, Guerra V, et al. Epidemiology of cholelithiasis in southern Italy. Part II: Risk factors. Eur $\mathcal{F}$ Gastroenterol Hepatol 1996;8:585-93.

12 Heath D, Williams DR. Man at high altitude. The pathophysiology of acclimatization and adaptation. New York: Churchill Livingstone, 1981:204.

13 Van Liere EJ, Crabtree WV, Northup DW, et al. Effect of anoxic anoxia on propulsive motility of the small intestine. Proc Soc Exp Biol Med 1948; 331-2.

14 Trotman BW, Bernstein SE, Balistreri WF, et al. Hemolysisinduced gallstones in mice: increased unconjugated bilirubin in hepatic bile predisposes to gallstone formation. Gastroenterology 1981;81:232-6.

15 Jorgensen T. Gallstones in a Danish population. Relation to weight, physical activity, smoking, coffee consumption, and diabetes mellitus. Gut 1989;30:528-34

6 Kahn H, Sempos T. Statistical methods in epidemiology. Oxford: Oxford University Press, 1989.

17 Carey V, Zeger SL, Diggle P. Modelling multivariate binary data with alternating logistic regressions. Biometrika 1993; 80: $517-26$

18 Barbara L, Sama C, Morselli AM, et al. A population study on the prevalence of gallstone disease: The Sirmione study. Hepatology 1987;7:913-17.

19 Maurer KR, Everhart JE, Knowler WC, et al. Risk factors for gallstone disease in the Hispanic populations of the United States. Am f Epidemiol 1990;131:836-44. 